\section{Bewährte Phytotherapie}

mmer mehr Patienten fragen nach pflanzlichen Präparaten als Alternative oder Ergänzung zur konventionellen Pharmakotherapie. Ein handliches Kompendium, das schnell und gezielt Auskunft gibt über bewährte Phytopharmaka unter Berücksichtigung von Leitlinien und Cochrane Reviews, ist deshalb in der täglich Praxis eine gute Hilfe.

Die 5. Auflage der „PhytoPraxis“ wurde auf den aktuellen Wissensstand gebracht und erweitert - ein Buch für alle, die Phy- topharmaka gezielt in der Therapie einsetzen oder empfehlen möchten. Es zeigt die Möglichkeiten einer rationalen Phytotherapie - praxisbezogen und wissenschaftlich belegt - und enthält zahlreiche Tipps für die tägliche Patientenversorgung.

Das Buch ist indikationsbezogen strukturiert, listet wirksamkeitsbelegte Substanzen mit Präparatebeispielen und Dosierung auf und bietet eine monographische Darstellung der pflanzlichen Wirkstoffe.
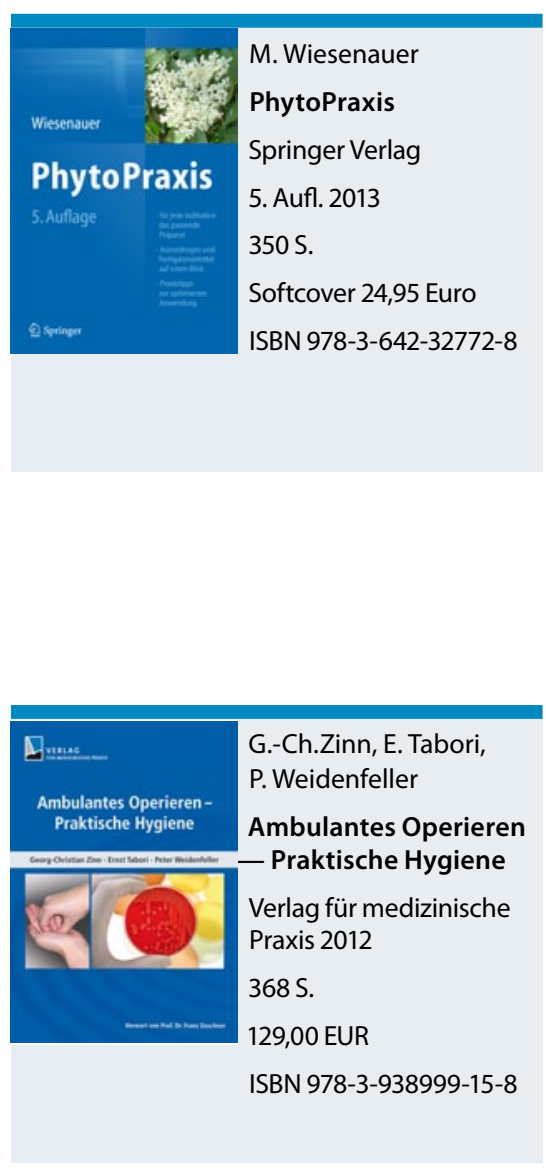

tenden Aspekten und die persönliche Lehrmeinung des Autors wird nicht immer klar als solche deutlich.

Trotz dieser Schwächen ist das Buch als Begleiter für die Praxis und als (Wieder-)Einstieg in das Thema gut geeignet. Nils-Olaf Hübner

gisch und didaktisch gut gemacht. Sprach-

insbesondere bei der Verdichtung in den „Memos“ z.T. etwas grob. Hier leidet die nötige Differenzierung zwischen widerstrei-

\title{
Vom Neandertal in die Philharmonie
}

A ls einzige Spezies besitzt der Mensch zwei lautliche Kommunikationssysteme: Sprache und Musik. Der evolutionäre Vorteil der Sprache zur Informationsübermittlung ist offensichtlich. Warum sich Musik als weiteres Kommunikationssystem entwickelte, wird bis heute diskutiert.

Im ersten Teil des Buches stellt der Autor die evolutionären Grundlagen der Musikwahrnehmung und des Musizierens dar. Die Vorläufer des Musizierens im Tierreich und die Rekonstruktionen des Musiklebens in der Steinzeit sind dabei die Ausgangspunkte.
Spezielle Erkenntnisse zur Neurobiologie sind die Schwerpunkte der nächsten beiden Kapitel. Dabei werden die Anpassungen des Zentralnervensystems bei professionellen Musikern ausführlich geschildert - einschließlich des Verlusts feinmotorischer Fertigkeiten bei höchstbegabten Virtuosen („Musikerkrampf" etwa bei Robert Schumann).

Weitere wichtige Aspekte sind die noch nicht ausgeschöpften heilenden Potenziale und die große Macht der positiven Emotionen, die durch Musik ausgelöst werden.

red

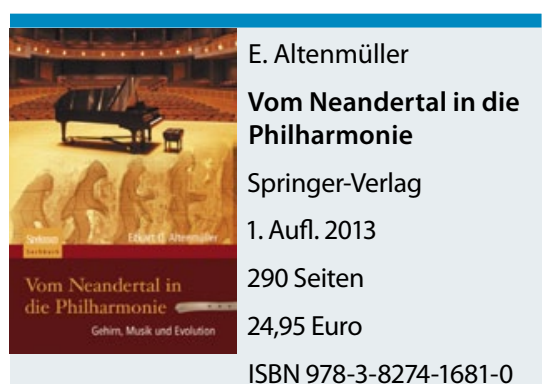

